Brazilian Journal of Applied Technology for Agricultural Science, Guarapuava-PR, v.9, n.1, p.91-103, 2016

\section{Cientific Paper}

\section{Resumo}

A identificação de velocidade limite para realizar a semeadura é importante para aproveitar as máquinas com sistema pneumático, mas também é necessário manter plantabilidade adequada. Diante desta problemática, o objetivo do presente trabalho foi avaliar o desempenho da plantabilidade de semeadoras pneumática na implantação da cultura da soja no cerrado piauiense. $\mathrm{O}$ trabalho foi

\title{
Desempenho da plantabilidade de semeadoras pneumática na implantação da cultura da soja no cerrado piauiense - Brasil
}

GuilhermeAugusto Bertelli ${ }^{1}$ Sidnei Osmar J adoski ${ }^{2}$ Murilo da Luz Dolato Leandro Rampim² Marcio Furlan Maggi ${ }^{4}$ desenvolvido no município de Baixa Grande do Ribeiro, sul do estado do Piauí. O experimento foi organizado em delineamento inteiramente casualizado (DIC) com arranjo fatorial (2x4), com três repetições. Sendo assim, o primeiro fator foi composto pelos modelos de semeadoras John Deere ${ }^{\circledR}$ (BT2117 e DB740) e o segundo fator, quatro velocidades de deslocamento das semeadoras durante a operação (V1 = 5,6 km h-1, V2 = 7,0 km h-1, V3 $\left.=8,6 \mathrm{~km} \mathrm{~h}^{-1} \mathrm{e} \mathrm{V4}=10,0 \mathrm{~km} \mathrm{~h}^{-1}\right)$. A plantabilidade foi avaliada através da verificação do número de plantas/ sementes distribuídos com as semeadoras, uniformidade de plantio, espaçamento aceitável, falho e duplo entre plantas. Na semeadora John Deere ${ }^{\circledR}$ modelo 2117, com aumento da velocidade de semeadura de 5,6 $\mathrm{km} \mathrm{h}^{-1}$ para $10,0 \mathrm{~km} \mathrm{~h}^{-1}$, o número de plantas por metro linear fica próximo ao estabelecido na regulagem da máquina. Já para a semeadora John Deere ${ }^{\circledR}$ modelo DB74, o valor de número de plantas fica abaixo do esperado, com média de 8,76 plantas $\mathrm{m}^{-1}$, (resultado de possível falha na regulagem/calibração da máquina antes de instalar o experimento). Para ambas as semeadoras, a percentagem de espaçamentos aceitáveis diminui conforme aumenta-se a velocidade de deslocamento, e os espaçamentos falhos aumentam com incremento na velocidade, consequentemente reduz a uniformidade de plantio.

Palavras chave: Glycine max, implantação da soja, dosador de semente, distribuição de sementes, população de plantas, estande de plantas.

\section{Plantability performance of pneumatic seeders in the soybean culture implantation in the Piaui cerrado - Brasil}

\begin{abstract}
The identification of limit speed to make the sowing is important to take advantage of machines with pneumatic system, but is also necessary maintain adequate plantability. Faced with this problem, the objective of this study was to evaluate the performance of plantability of the pneumatic seeders in soybean implantation in Piauí cerrado (savanna). The study was conducted in the municipality of Baixa Grande do Ribeiro, southern Piauí state. The experiment was arranged in a completely randomized design (CRD) in
\end{abstract}

\footnotetext{
Received at: 10/12/15 Accepted for publication at: 28/03/16

1 Eng. Agrônomo, Universidade Estadual do Centro-Oeste-UNICENTRO. Guarapuava-Pr. Email: guilhermeb@yahoo.com

2 Eng. Agrônomo, Dr. Prof. Depto Agronomia. Universidade Estadual do Centro-Oeste-UNICENTRO. Guarapuava-Pr. Email: sjadoski@ unicentro.br, lrampim@unicentro.br

3 Eng. Agrônomo - INSOLO. Email: dolato@insolo.ciom.br.

4 Eng. Agrícola, Dr. Prof. Depto Ciências Exatas e Tecnologia. Universidade Estadual do Oeste do Paraná-UNIOESTE Cascavel-Pr. Email: marcio.maggi@unioeste.br.
}

Applied Research \& Agrotechnology $v 9$ n1 jan/apr. (2016)

Print-ISSN 1983-6325 (On line) e-ISSN 1984-7548 
Bertelli et al. (2016)

factorial arrangement $(2 \times 4)$, with three replications. Therefore, the first factor was compound by models seeders John Deere ${ }^{\circledR}$ (BT2117 and DB740) and the second factor, by four forward speeds of the seeder during operation ( $\left.\mathrm{V} 1=5,6 \mathrm{~km} \mathrm{~h}^{-1}, \mathrm{~V} 2=7,0 \mathrm{~km} \mathrm{~h}^{-1}, \mathrm{~V} 3=8,6 \mathrm{~km} \mathrm{~h}^{-1} \mathrm{e} \mathrm{V4}=10,0 \mathrm{~km} \mathrm{~h}^{-1}\right)$. The plantability was evaluated by checking the number of plants / seeds distributed with seeders, uniformity of planting, spacing acceptable, flawed and double between plants. In seeder John Deere ${ }^{\circledR}$ model 2117, with increased speed seeding of $5.6 \mathrm{~km}$ $\mathrm{h}^{-1}$ to $10.0 \mathrm{~km} \mathrm{~h}^{-1}$, the number of plants per linear meter is close to the established regulation of the machine. As for the seeder John Deere ${ }^{\circledR}$ DB74 model, the plant number value is lower than expected, with an average of 8.76 plants $\mathrm{m}^{-1}$, (possible result failed regulation / machine calibration before installing the experiment). For both seeders, the percentage of acceptable spacings decreases as increases the travel speed, and flawed spacing increase with increase in speed, thus reducing the uniformity of planting.

Key words: Glycine max, soybean sowing, seed feeder, distribution of seeds, plant population, stand of plants.

\section{Rendimiento de sembradoras neumáticas en la implantación de cultivo de soja en el Cerrado Piauíense - Brasil}

\section{Resumen}

La identificación de la velocidad límite para hacer la siembra es importante para provechar las máquinas con sistema neumático, pero es también necesario mantener la plantabilidad adecuada. Ante este problema, el objetivo del este estudio fue evaluar el desempeño de la plantabilidad de sembradoras neumáticas en la implantación de soja en el cerrado Piauíense. El estudio se realizó en el municipio de Baixa Grande do Ribeiro, en el sur del estado de Piauí. El experimento fue dispuesto en un diseño completamente al azar (DCA) con arreglo factorial $(2 \times 4)$, con tres repeticiones. Por lo tanto, el primer factor fue compuesto por los modelos de sembradoras John Deere ${ }^{\circledR}$ (BT2117 y DB740) y el segundo factor de cuatro velocidades operación de la sembradora (V1 $=5,6 \mathrm{~km} \mathrm{~h}^{-1}, \mathrm{~V} 2=7,0 \mathrm{~km} \mathrm{~h}^{-1}, \mathrm{~V} 3=8,6 \mathrm{~km} \mathrm{~h}^{-1} \mathrm{e} \mathrm{V4}=10,0 \mathrm{~km} \mathrm{~h}^{-1}$ ). Se evaluó la plantabilidad mediante la comprobación del número de plantas/semillas distribuidas con sembradoras, la uniformidad de la siembra, el espaciamiento aceptable, deficiente y doble entre las plantas. En la sembradora John Deere ${ }^{\circledR}$ modelo 2117, con un aumento de la velocidad de siembra de 5,6 km h-1 hasta 10,0 $\mathrm{km} \mathrm{h}^{-1}$, el número de plantas por metro lineal se presentó a cerca de la regulación establecida de la máquina. En cuanto a la sembradora modelo John Deere ${ }^{\circledast}$ DB74, el valor del número de plantas fue menor de lo esperado, con un promedio de 8,76 plantas $\mathrm{m}^{-1}$, (resultado de posible falla de calibración regulación/máquina antes de instalar el experimento). Para ambas sembradoras, el porcentaje de espacios aceptables disminuye a medida que aumenta la velocidad de desplazamiento, y los espacios defectuosos aumentan con el aumento de la velocidad, reduciendo así la uniformidad de la siembra.

Palabras clave: Glycine max, siemba de la soja, dosificador de semillas, distribución de semillas, población de plantas, stand de plantas.

\section{Introdução}

A soja (Glycine max L.) pertence à família Fabaceae, de origem do continente asiático, especificamente na China, sendo de grande importância ao agronegócio mundial por ser uma commodity agrícola. Para o Brasil, apresenta grande valor no mercado financeiro, fazendo dele o segundo colocado na produção mundial do grão e um dos principais países exportadores (DEJNEKA, 2015).
Destaca-se que a cultura da soja tem apresentado crescimento exponencial em produtividade em todas as regiões do Brasil (MINUZZI et al., 2009).

Portanto, para que a cultura possa expressar todo seu potencial durante o ciclo, necessita-se que o processo de semeadura seja bem realizado, respeitando a plantabilidade, que evidencia a quantidade de plantas com espaçamentos corretos por unidade de área (SCHUCH e PESKE, 2012), possibilitando 


\author{
Desempenho da plantabilidade de... \\ Plantability performance of ... \\ Rendimiento de sembradoras neumáticas en la...
}

alcançar população de plantas adequado distribuída uniformemente. A plantabilidade está presente na distribuição das sementes na linha de semeadura e, a melhor distribuição, é aquela em que as plantas ficam a mesma distância uma da outra; especificamente em condição que proporciona menor grau de competição entre as plantas, proporcionando maior rendimento por planta e consequentemente aumento na produtividade de grãos (HEIFFIG et al., 2006).

Para a cultura da soja, a distribuição de sementes é um fator tão importante, que os implementos responsáveis por esta função, são denominadas de semeadoras de precisão. Nestas máquinas, o mecanismo dosador de sementes ganha destaque, pois são responsáveis por individualizar as sementes contidas no reservatório, sem danificá-las e distribuí-las uniformemente, garantindo a precisão do sistema (COPETTI, 2016).

A semeadura de uma lavoura é uma das principais etapas, por isso exige que seja muito bem planejada, sendo dependente da regulagem adequada do implemento e seleção de velocidade de deslocamento da máquina compatível a distribuição adequada.

No cerrado brasileiro, existem mais de 50 milhões de hectares de terras virgens e aptas para o desenvolvimento da cultura da soja (NUNES, 2015), sendo necessário aproveitar a condições de solo, regularidade de chuva e janela de semeadura, sobretudo com uso adequado das máquinas durante a distribuição de sementes para potencializar o rendimento das culturas.

Trabalhos têm mostrado que a produtividade final é diretamente afetada pela velocidade de semeadura, pois este fator está associado a distribuição das sementes na linha. Para MADALOZ (2014), o excesso de velocidade na semeadura contribui para maior desuniformidade de profundidade das sementes, maior número de falhas e plantas duplas, resultando em competição intra-específica e desenvolvimento irregular. LACERDA (2015) destaca que a recomendação da Embrapa, quanto a velocidade de semeadura da soja, fique em torno de $4 \mathrm{a} 6 \mathrm{~km} \mathrm{~h}^{-1}$, sendo que valores superiores prejudicam a distribuição das sementes.

A reduzida janela de semeadura no cerrado exige aproveitar ao máximo o desempenho operacional das semeadoras, sendo fundamental para aproveitar o potencial das cultivares e a condição climática mais adequada para as plantas. Para elevar o desempenho operacional da semeadura tem-se necessidade de elevar a velocidade de semeadura, podendo comprometer a plantabilidade da cultura da soja. Outra opção, é aumentar a largura da semeadora, mas, em algumas situações já se utiliza máquinas de grande porte. Nesta situação, a identificação de velocidade limite para realizar a semeadura é importante para aproveitar as máquinas com sistema pneumático, mas também é necessário manter plantabilidade adequada.

Diante desta problemática, o objetivo do presente trabalho foi avaliar o desempenho da plantabilidade de semeadoras pneumática na implantação da cultura da soja no cerrado piauiense.

\section{Material e Métodos}

\section{Descrição do Local}

O trabalho foi desenvolvido na unidade de produção Galiléia Agroindustrial, pertencente a empresa Insolo Agroindustrial, localizada no município de Baixa Grande do Ribeiro, sul do estado do Piauí.

O experimento foi realizado em um talhão da unidade de produção. O solo da área apresentava $39,5 \%$ de argila e as seguintes características químicas, conforme análise de solo realizada antes da implantação da safra 2014/201: Ca, 3,27 cmolc $\mathrm{dm}^{-3} ; \mathrm{Mg}, 1,20$ cmolc dm-3; P, 37,25 mg dm${ }^{-3} ; \mathrm{K}, 35,0$ $\mathrm{mg} \mathrm{dm}{ }^{-3} ; \mathrm{MO}, 5,28 \% ; \mathrm{V} \%, 32,52 \%$.

No talhão não houve revolvimento de solo, sendo considerado sistema de semeadura direta. A área de realização do experimento contava com presença de plantas daninhas, como capim-papuã (Brachiaria plantaginea), fedegoso (Cassia occidentalis L.), corda-de-viola (Ipomea spp.), vassourinha de botão (Borreria verticillata L.), além de restos culturais de crotalária (Crotalaria juncea) e milheto (Pennisetum glaucum L.).

Implantação do experimento e tratamentos

Para avaliar a qualidade de semeadura, destinou-se um experimento para testar diferentes velocidades de semeadura em duas semeadoras.

O experimento foi organizado em delineamento inteiramente casualizado (DIC) com arranjo fatorial $(2 \times 4)$, com três repetições. Sendo assim, o primeiro fator foi modelos de semeadoras John Deere ${ }^{\circledR}$ (BT210 e DB740) e o segundo fator, 
quatro velocidades de deslocamento das semeadoras durante a operação (V1 = 5,6 $\mathrm{km} \mathrm{h}^{-1}, \mathrm{~V} 2=7,0 \mathrm{~km} \mathrm{~h}^{-1}$, $\mathrm{V} 3=8,6 \mathrm{~km} \mathrm{~h}^{-1}$ e V4 $=10,0 \mathrm{~km} \mathrm{~h}^{-1}$ ).

As duas semeadoras utilizadas foram da marca John Deere ${ }^{\circledR}$, sendo uma do modelo 2117 com 15 linhas tracionada por um trator Valtra ${ }^{\circledR}$ modelo BT210 e, outra, do modelo DB74, com 48 linhas tracionada por um trator John Deere ${ }^{\circledR}$ modelo 9510R. Cada linha das semeadoras foram compostas de: mecanismo dosador de sementes VacuMeterTM com disco horizontal perfurado, com 36 células e 184,5 mm de diâmetro; um disco de borda lisa, com 18 " de diâmetro, para o corte da palhada; tubo de semente curvado translúcido e as rodas controladoras da profundidade de semeadura, fechamento e compactação do sulco. Não foi utilizado adubo no momento da semeadura, tendo em vista que o mesmo foi aplicado em cobertura.

As regulagens nas máquinas foram realizadas para proporcionar distribuição média de 10,2 sementes $\mathrm{m}^{-1}$ com cultivar MSOY8644 IPRO, poder germinativo de $85 \%$. O espaçamento entrelinhas foi de $0,45 \mathrm{~m}$. As sementes foram tratadas com fungicida do grupo químico Tiofanato-metílico e Fluazinam (CERTEZA), com dose de $1.800 \mathrm{ml}$ para $1.000 \mathrm{~kg}$ de sementes. Foi utilizado inoculante líquido com bactérias do gênero Bradyrhizobium japonicum (GRAP NOD), com dose de $2.700 \mathrm{ml}$ para $1.000 \mathrm{~kg}$ de sementes. Nas caixas de semente foi utilizado polímero grafite para minimizar a rugosidade das sementes devido a utilização do tratamento de sementes.

\section{Descrição das semeadoras}

\section{Semeadora John Deere ${ }^{\circledR}$ Série 2100}

A Semeadora John Deere® Série 2100 Modelo 2117 é considerada de grande dimensão (Figura 1A), destinada a terrenos de topografia regular e para o sistema plantio direto em todas as condições de solo. Apresenta 15 linhas de semeadura com espaçamento de $45 \mathrm{~cm}$. As caixas de sementes são individuais, com sistema para distribuição de adubo com sulcador desencontrado. As caixas de adubo são feitas de polietileno rotomoldado, com capacidade de até $3600 \mathrm{~kg}$. O sistema dosador de adubo é do mecanismo ProMeterTM, sendo a regulagem da quantidade aplicada feita através da combinação de engrenagens de transmissão.
O sistema VacuMeterTM garante a dosagem de sementes por vácuo, utilizando a pressão negativa para sugar cada semente individualmente e mantê-las nas células do disco de sementes. Este mecanismo dosador de sementes é capaz de operar em velocidade de semeadura de até $12 \mathrm{~km} \mathrm{~h}^{-1}$, porém, a precisão da semeadura pode ser afetada em velocidade superior a $9 \mathrm{~km} \mathrm{~h}^{-1}$, afetam a distribuição longitudinal das sementes (JOHN DEERE®, 2016a).

Os discos sulcadores para sementes são do modelo Tru-VeeTM, em forma de V com lados perfeitos. $\mathrm{O}$ tubo condutor de sementes tem face plana, com uma superfície curvada contínua que provoca a entrada da semente no tubo e faz deslizar suavemente até ser expelida. O sistema de transmissão é do tipo mecânico, com caixas de engrenagens posicionadas nos lados da semeadora, sendo o monitoramento de sementes realizado por monitor dentro do trator.

\section{Semeadora John Deere ${ }^{\circledast}$ Série DB}

A semeadora John Deere ${ }^{\circledR}$ Série DB - Modelo DB74 também é considerada de grande dimensão (Figura 1B), destinada a terrenos de topografia regular e para o sistema plantio direto. A semeadora é composta por 48 linhas com espaçamento de $45 \mathrm{~cm}$. Este implemento conta com o sistema de caixa central de sementes, com total de três tanques centralizados na máquina, com capacidade de armazenamento de $3260 \mathrm{~kg}$ de sementes. O processo de distribuição de sementes é feito por uma turbina acionada hidraulicamente que move as sementes dos tanques às linhas de semeadura. Este sistema se utiliza da pressão de ar positiva que serve como um impulso para as sementes saírem da caixa maior em direção às caixas menores individualizadas.

O sistema VacuMeterTM também é utilizado para dosar as sementes. Os discos sulcadores para sementes são do modelo Tru-VeeTM, em forma de $\mathrm{V}$ com lados perfeitos. O tubo condutor de sementes tem face plana, com uma superfície curvada contínua que provoca a entrada da semente no tubo e faz deslizar suavemente até ser expelida. O sistema de transmissão é do tipo Pro-Shaft, feita por cabo de aço flexível, dispensando as caixas de engrenagens. Outo comando é o RowCommandTM, na qual o sistema monitora o posicionamento da linha de semeadura e, quando detectar a eminência de sobreposição, ocorre o cancelamento automático da distribuição nas linhas que estão sobrepondo (JOHN DEERE®, 2016b). 


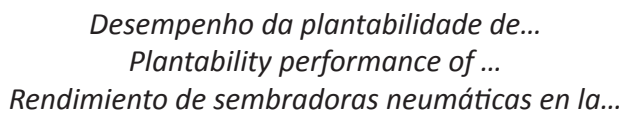

O diferencial desta semeadora é a capacidade de semear até 18 ha $\mathrm{h}^{-1}$. Entretanto, este fato é atribuído ao tamanho da máquina e a ausência do sistema de distribuição de adubo, sendo esta etapa feita por outro implemento.

\section{Avaliações}

A avaliação da plantabilidade da cultura da soja proporcionada pelas duas semeadoras em diferentes velocidades foram realizadas 15 dias após a semeadura. Foi avaliada a distância entre plantas ou distância entres plantas e sementes não germinadas, com medidas realizadas com auxílio de trena em cada parcela, com área útil oriunda de cinco linhas de semeadura numa extensão de $2 \mathrm{~m}$ cada, totalizando $4,5 \mathrm{~m}^{2}$.

Com base no espaçamento entre plantas foi calculado o número de sementes por metro e também a uniformidade de semeadura, em percentagem. Para o cálculo de uniformidade foram utilizados os valores de espaçamentos duplos, falhas de semeadura e espaçamento adequado, conforme espaçamento esperado, seguindo metodologia proposta por KURACHI et al. (1989). A distância média entre plantas/sementes ideal, seria espaçamento de 0,098 $\mathrm{m}$, pois a regulagem foi para depositar 10,2 sementes por metro no sulco (espaçamento médio esperado). Para tal, foram considerados duplos os espaçamentos entre plantas ou entre plantas e sementes não germinadas de 0,5 vezes (menor que $0,049 \mathrm{~m}$ ). Foram considerados falhas o espaçamento superior a 1,5 vezes (maior que $0,147 \mathrm{~m}$ ).

Com base nos valores de espaçamentos duplos, falhas e total de sementes foi realizado o cálculo da uniformidade de semeadura para cada unidade experimental. De acordo com Silva et al. (1998), a uniformidade de plantio pode ser calculada pela seguinte equação:

Sendo: $\mathrm{UP}=$ uniformidade de plantio (\%); $\mathrm{Z}=$ número de espaçamentos entre plantas de soja maior que $0,147 \mathrm{~m}$ e menor que $0,049 \mathrm{~m}$, considerado como falha e como duplo respectivamente; $\mathrm{N}=$ número total de espaçamentos medido.

\section{Análise estatística}

Os dados obtidos de número de plantas por metro, espaçamentos falhos, duplos, aceitáveis e uniformidade de plantio foram submetidos a análise de variância a 5\% de probabilidade de erro. Quando pertinente, as semeadoras foram comparadas pelo teste $\mathrm{F}$ conclusivo em caso de efeito significativo (apenas duas semeadoras), assim como foi realizada análise de regressão para as velocidades de deslocamento ao identificar efeito significativo da velocidade ou da interação semeadora e velocidade. Os dados foram analisados através do programa estatístico SISVAR 5.1 (FERREIRA, 2011).
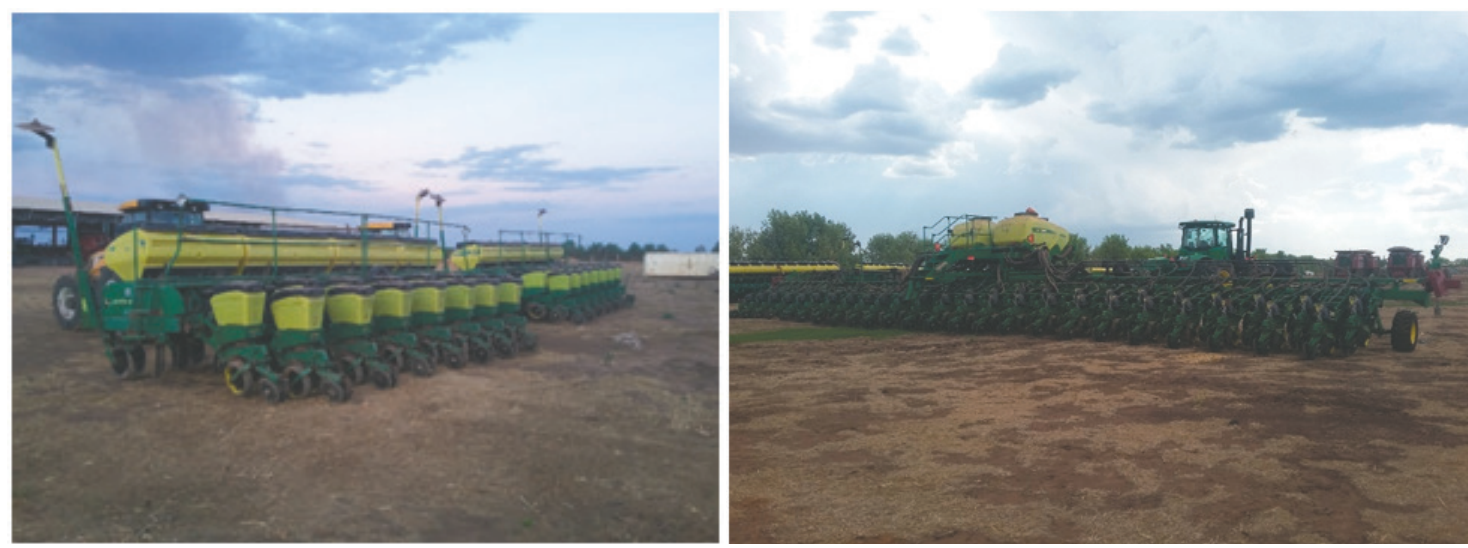

Figura 1. (A) Semeadora John Deere ${ }^{\circledR}$ Série 2100, Modelo 2117 com 15 linhas de semeadura com espaçamento de $45 \mathrm{~cm}$ entrelinhas e (B) Semeadora John Deere ${ }^{\circledR}$ Série DB, Modelo DB74 com 48 linhas de semeadura com espaçamento de $45 \mathrm{~cm}$ entre linhas. Baixa Grande do Ribeiro, PI, 2015. 


\section{Resultados e Discussão}

Na Tabela 1 são apresentados os resultados da análise de variância para o número de plantas $\mathrm{m}^{-1}$. Verifica-se que a fonte de variação modelo de semeadora apresentou efeito significativo, enquanto velocidade e a interação não apresentaram significância. Foi plotado os valores de número de plantas $\mathrm{m}^{-1}$ em cada velocidade para cada semeadora, evidenciando apenas a diferença entre as semeadoras (Figura 2).

Para a uniformidade de semeadura (\%), a análise de variância dos dados mostrou que a fonte de variação velocidade apresentou efeito significativo, mas não foi observado efeito significativo entre modelo de semeadora e a interação entre os fatores (Tabela 1). Em relação a distribuição das plantas na linha, foi verificado efeito significativo para modelo de semeadora nas variáveis espaçamentos falhos, duplos e aceitáveis, e efeito significativo para velocidade em espaçamentos duplos e aceitáveis. Por outro lado, não houve efeito significativo para espaçamentos falhos para velocidade, assim como não houve efeito significativo na interação de espaçamentos falhos, duplos e aceitáveis.

A semeadora 2117 apresentou valores superiores de número de plantas $\mathrm{m}^{-1}$, independente da velocidade, em relação a DB 74 (Figura 2). Para a semeadora John Deere ${ }^{\circledR}$ modelo DB 74 o valor médio de plantas por metro foi igual a 8,76 . Para a semeadora modelo 2117, o valor médio foi de 10,66. A utilização da semeadora modelo DB 74 independente da velocidades, deve-se atentar a redução do número de sementes que são depositadas, visto que na regulagem inicial do número de sementes havia estabelecido 10,2 sementes $\mathrm{m}^{-1}$, sendo necessário calibrar adequadamente o equipamento antes de iniciar a operação de semeadura.

Na semeadora John Deere ${ }^{\circledR}$ DB74, o número de plantas permanece abaixo do estabelecido durante a regulagem. Este modelo de semeadora é considerado como uma das mais tecnificadas, sendo a regulagem do número de sementes por metro feito dentro da cabine do trator através do monitor da máquina com o ajuste da população de plantas ha-1. Na semeadora John Deere® DB74 deve-se atentar ao momento de realizar regulagem para verificar se o sistema automático de regulagem está calibrado corretamente.

Os resultados encontrados demonstram que a calibração da máquina realizada anteriormente a realização do experimento não foi eficiente. Em estudo semelhante, CORTEZ et al. (2006) verificaram que os valores do estande inicial de soja não foram afetados pelas diferentes culturas, manejos e marchas do trator na operação de semeadura. Da mesma forma, BRANQUINHO (2003) a testar a semeadura da soja, verificaram que o número de plantas não foi afetado com alteração do manejo e marcha do trator. Desta forma, verifica-se que o número de sementes distribuídos tem alcançado níveis adequados, por outro lado, ressalta-se que a presença da quantidade de sementes não é suficiente para mostrar se a cultura terá condições de alcançar o máximo de produtividade, pois a uniformidade de distribuição das sementes interfere na produtividade da soja (TOURINO, REZENDE e SALVADOR, 2002).

Tabela 1. Análise de variância para as variáveis número de plantas $\mathrm{m}^{-1}$, uniformidade de plantio (\%),

\begin{tabular}{|c|c|c|c|c|c|c|}
\hline \multirow{2}{*}{$\begin{array}{l}\text { Fonte de } \\
\text { variação }\end{array}$} & \multirow{2}{*}{ GL } & \multirow{2}{*}{$\begin{array}{l}\text { Número de } \\
\text { plantas } \mathbf{m}^{-1}\end{array}$} & \multirow{2}{*}{$\begin{array}{l}\text { Uniformidade } \\
\text { de plantio (\%) }\end{array}$} & \multicolumn{3}{|c|}{ Espaçamentos } \\
\hline & & & & Falhos & Duplos & Aceitáveis \\
\hline & & \multicolumn{5}{|c|}{ F calculado } \\
\hline Semeadora (S) & 1 & 70,77 * & $2,82 \mathrm{~ns}$ & 35,69 ** & $39,70 * *$ & 4,61 * \\
\hline Velocidade (V) & 3 & $1,92 \mathrm{~ns}$ & $3,37^{*}$ & $1,01 \mathrm{~ns}$ & $4,21^{*}$ & 4,84 * \\
\hline$V^{*} \mathrm{~S}$ & 3 & $1,35 \mathrm{~ns}$ & $0,08 \mathrm{~ns}$ & $0,31 \mathrm{~ns}$ & $1,24 \mathrm{~ns}$ & $0,03 \mathrm{~ns}$ \\
\hline Média & & 9,71 & 67,23 & 16,97 & 15,27 & 67,75 \\
\hline C.V. $(\%)$ & & 5,72 & 7,06 & 27,13 & 18,76 & 6,50 \\
\hline
\end{tabular}

* significativo a $5 \%$ de probabilidade de erro; ** significativo a 1\% de probabilidade de erro; ns não significativo a $5 \%$ de probabilidade de erro; C.V. = coeficiente de variação; GL = graus de liberdade. 


\section{Desempenho da plantabilidade de... \\ Plantability performance of ...

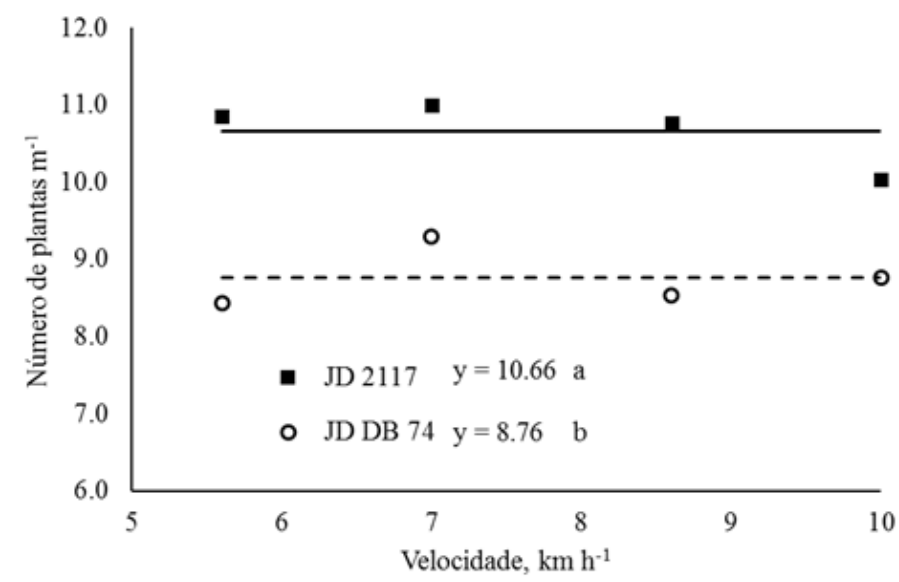

Figura 2. Número de plantas $\mathrm{m}^{-1}$ entre as semeadoras John Deere® 2117 e John Deere ${ }^{\circledR}$ DB74 em função da velocidade de semeadura da soja. Baixa Grande do Ribeiro, PI, 2015.

A regulagem adequada da semeadora associado a sementes de qualidade (elevada germinação e alto vigor), complementam para almejar elevado teto de produtividade (BORTOLOTTO, 2014). Portanto, para atingir essa qualidade de semeadura, alguns fatores devem ser levados em consideração juntamente com a velocidade de semeadura adequada, assim como escolha do disco de sementes, regulagem da pressão do vácuo, distância entre semente e adubo, contato solo/ semente e a profundidade de semeadura.

Na Figura 3 é apresentada a curva de regressão para a uniformidade (\%) em função da velocidade de semeadura, independente da semeadora. A curva de regressão apresentou ajuste no modelo linear, apresentando maior uniformidade com velocidade de $5,5 \mathrm{~km} \mathrm{~h}^{-1}$. Verifica-se que com o aumento da velocidade de semeadura ocorre redução da uniformidade.

Para os dois modelos de semeadora, foi verificada diferença na uniformidade entre as semeadoras, sendo que a semeadora John Deere ${ }^{\circledR}$ modelo 2117 possui uniformidade média de 65,68\% inferior ao modelo DB74, com uniformidade média de 68,85\%. Casão Junior, Araújo e Ralisch (2000), em um trabalho semelhante, avaliaram o desempenho de uma semeadora e comprovaram que, mesmo com duas velocidades de semeadura diferente $\left(4,5 \mathrm{~km} \mathrm{~h}^{-1} \mathrm{e}\right.$ $\left.8,0 \mathrm{~km} \mathrm{~h}^{-1}\right)$, a distribuição transversal das sementes de soja foi muito boa, principalmente devido aos baixos valores de coeficiente de variação.
Sobretudo, TOURINO, REZENDE e SALVADOR (2002), concluíram que o aumento da uniformidade de semeadura, contribuiu para redução do acamamento, assim como para o aumento da produtividade da soja. Desta forma, a semeadora modelo DB74 proporciona melhor qualidade na implantação da cultura, constatado pela uniformidade de plantio, apresentando maior possibilidade de alcançar nível produtivo mais elevado, pois consegue deixar as plantas melhor distribuição na linha de semeadura; tanto favorecendo melhor aproveitamento do sistema solo pelas raízes para absorver água e nutrientes, assim como reduzir a competitividade por espaço, minimizando possível acamamento, principalmente em anos agrícolas em que ocorra elevada precipitação pluviométrica.

Em trabalho realizado por HEIFFIG et al. (2006), constataram que, o fechamento nas entrelinhas nos estádios iniciais da cultura da soja, possibilitaram o desenvolvimento precoce do seu aparato fotossintético. Já a desuniformidade na distribuição longitudinal de plantas, segundo JASPER et al. (2011), implicou em aproveitamento ineficiente dos recursos disponíveis, como luz, água e nutrientes. Além disso, o aparecimento de plantas daninhas pode ser favorecido pela presença de espaços entre uma planta e outra. Sendo assim, uma distribuição de sementes regular, respeitando distância equivalente entre as sementes, vão garantir condições iguais para o desenvolvimento inicial das 
plântulas e posterior fechamento do espaço entre as linhas de semeadura.

A distribuição longitudinal das plantas foi influenciada pelo fator velocidade de semeadura para ambos os modelos de semeadoras (Figura 5 e 6). Para ambos os modelos de semeadora, quanto maior a velocidade, menor a quantidade de espaçamentos aceitáveis e maior a quantidade de espaçamentos duplos, mantendo inalterado os espaçamentos falhos (Figura 6). Analisando a produtividade por área em uma lavoura de soja, PINTO (2014) observou que, a presença de falhas no estande, acarretam decréscimo de produtividade que vão de 6 a 30\%, dependendo do tamanho da falha. RAMBO et al. (2002) afirmaram que arranjos que proporcionam melhor distribuição das plantas na área colaboram com a penetração de luz no dossel da soja, incrementando produção de fotoassimilados e rendimento de grãos. Basicamente, para que uma planta possa atingir o seu máximo potencial de produção, deve-se garantir a ela condições de clima e solo suficientes para evitar a competição entre plantas (SCHUCH e PESKE, 2012).

HEIFFG et al. (2006) indicam que, redução no espaçamento entrelinhas sem o devido ajuste na densidade de plantas na linha, pode contribuir para o acamamento das plantas. Já a presença de poucas plantas por metro, culmina em plantas de menor porte, mais ramificadas, com maior probabilidade de perdas na colheita. Em outro trabalho semelhante, JASPER et al. (2011) afirmaram que o acúmulo de plantas pode provocar o desenvolvimento de plantas de maior porte, porém menos ramificadas, com menor produção individual, diâmetro de haste reduzido e mais propensas ao acamamento.

Tendo em vista as características fisiológicas das plantas de soja, KOMATSU, GUADAGNIN e BORGO (2010), em pesquisa realizada avaliando o efeito do espaçamento de plantas de soja, observaram que quanto maior a competição intraespecífica, menor foi a produtividade. Sabendo disto, a realização da semeadura da soja dentro do conceito de plantabilidade, principalmente em velocidade adequada para semeadura, garante uniformidade entre as plantas e permite atingir maior produtividade. Corroborando com estes resultados, CORTEZ et al. (2006) em avaliação com uma semeadoraadubadora pneumática, também observaram que ao aumentar a velocidade de $4,24 \mathrm{~km} \mathrm{~h}^{-1}$ para $6,0 \mathrm{~km}$

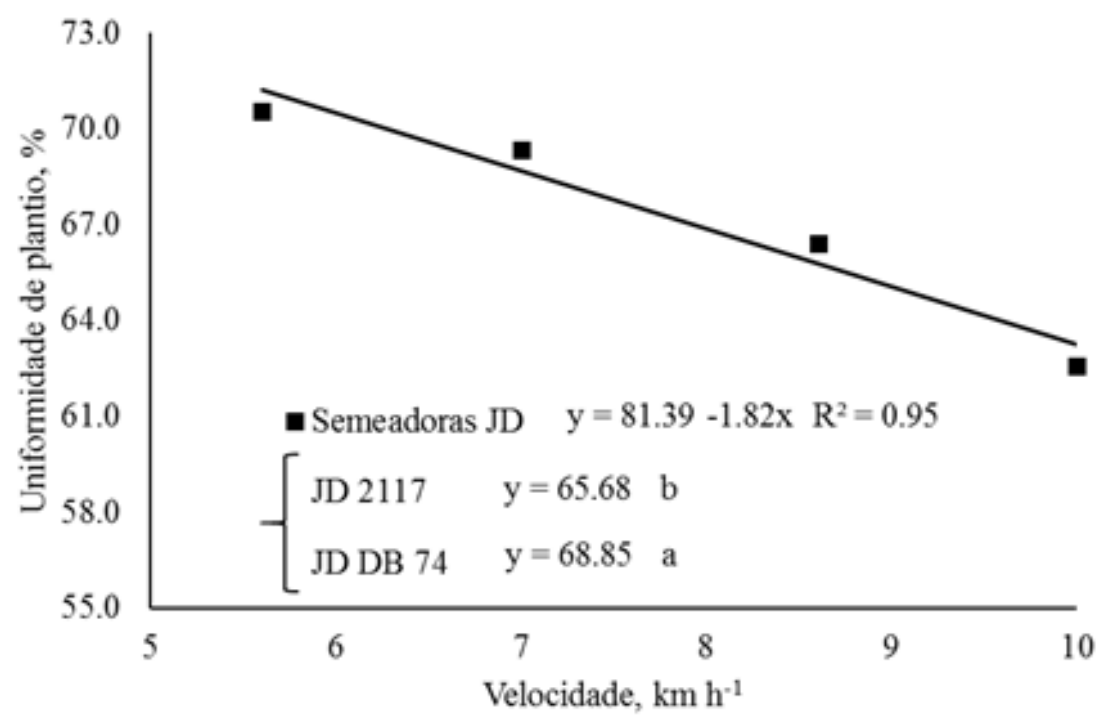

Figura 3. Uniformidade de plantas em função da velocidade de semeadura para a média das duas semeadoras John Deere® modelos 2117 e DB74. Baixa Grande do Ribeiro, PI, 2015. 
Desempenho da plantabilidade de... Plantability performance of ... Rendimiento de sembradoras neumáticas en la...
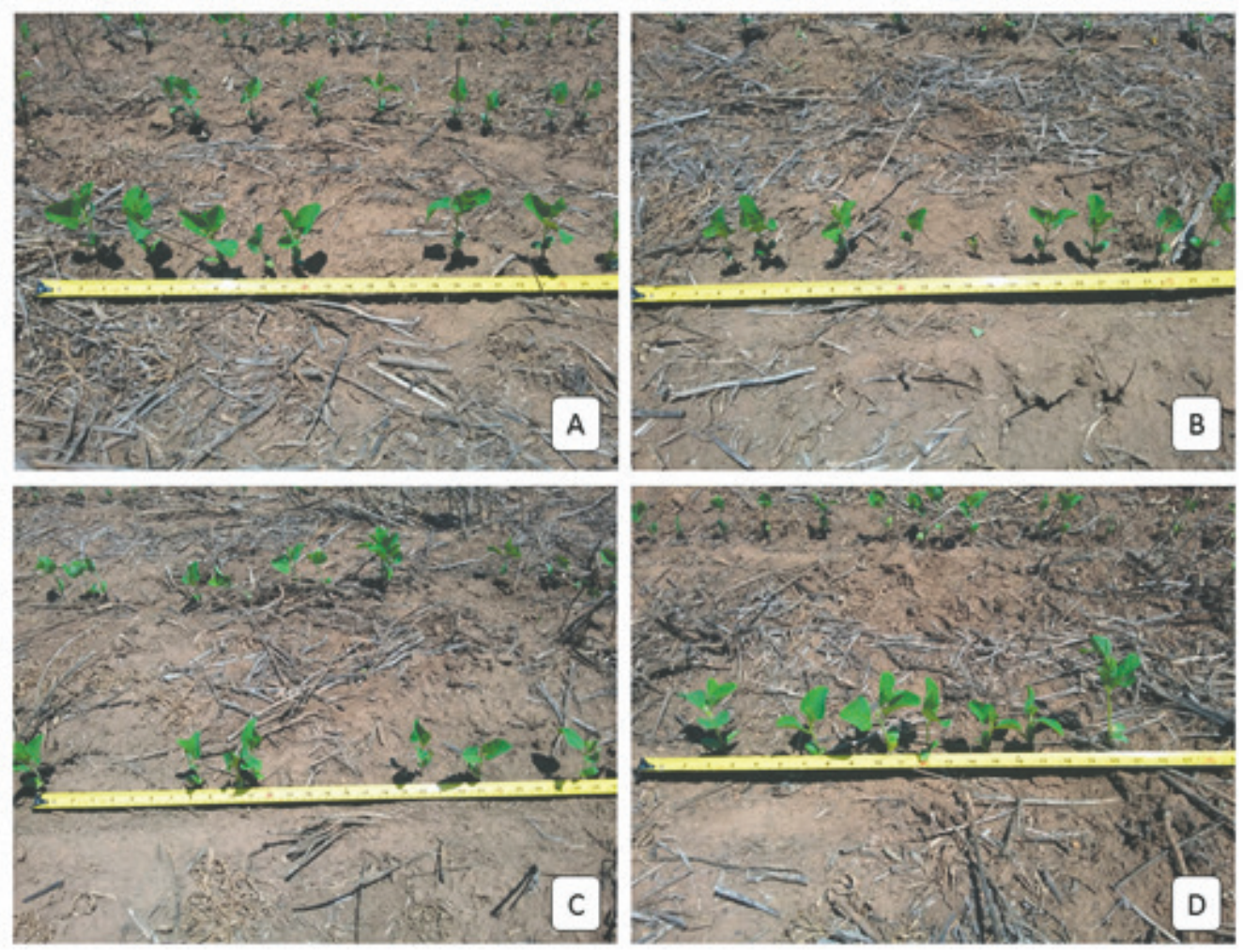

Figura 4. Distribuição das plantas em função da velocidade de semeadura, sendo $A=5,6 \mathrm{~km} \mathrm{~h}^{-1} ; \mathrm{B}=7,0 \mathrm{~km}$ $\mathrm{h}^{-1} ; \mathrm{C}=8,6 \mathrm{~km} \mathrm{~h}^{-1}$ e D $=10,0 \mathrm{~km} \mathrm{~h}^{-1}$ para a semeadora John Deere ${ }^{\circledR}$ modelo 2117. Baixa Grande do Ribeiro, PI, 2015

$\mathrm{h}^{-1}$, o número de espaçamentos aceitáveis é menor e aumenta-se o número de falhas. COPETTI (2003) identificaram que o percentual de espaçamentos aceitáveis, duplos e falhos passou de $84,7 \%$ para $61 \%$, $8,2 \%$ para $14,1 \%$ e $7,1 \%$ para $24,9 \%$, respectivamente, após a velocidade de semeadura passar de $4,5 \mathrm{~km}$ $\mathrm{h}^{-1}$ para $8,0 \mathrm{~km} \mathrm{~h}^{-1}$. Por outro lado, BRANQUINHO (2003) afirma que não houve diferença entre a distribuição longitudinal das sementes de soja ao alterar a velocidade de semeadura para diferentes semeadoras com mesmo mecanismo de distribuição de sementes. KLEIN et al. (2002) afirmaram que não houve diferença nos espaçamentos aceitáveis, duplos e falhas para aumento na velocidade de semeadura da soja com semeadora pneumática.

A redução de espaços aceitáveis (Figura 6) não evidenciam diferença na produtividade com a implantação da cultura da soja, visto que a cultura da soja tem possibilidade de compensar espaços por ausência de plantas. Contudo, a elevação de espaços duplos evidencia a possibilidade de ocorrer duas plantas muito próximas, explorando o mesmo volume de solo para absorver água e nutrientes, assim como competir por espaço para receber radiação solar, além de poder elevar o sombreamento. Tal fato, pode repercuti em menor uniformidade de semeadura (Figura 3), interferindo negativamente na produtividade da cultura da soja.

Ao analisar os resultados encontrados no trabalho, justifica-se que o valores encontrados para as variações de número de plantas $\mathrm{m}^{-1}$, uniformidade de semeadura, espaçamentos aceitáveis, duplos e falhas, ocorre para ambos os modelos de semeadoras, devido algumas situações observadas durante a operação de semeadura. Uma delas, seria a utilização de um disco de sementes com 36 furos, ou seja, a medida em que se aumenta a velocidade de deslocamento da máquina, o disco tem um tempo 

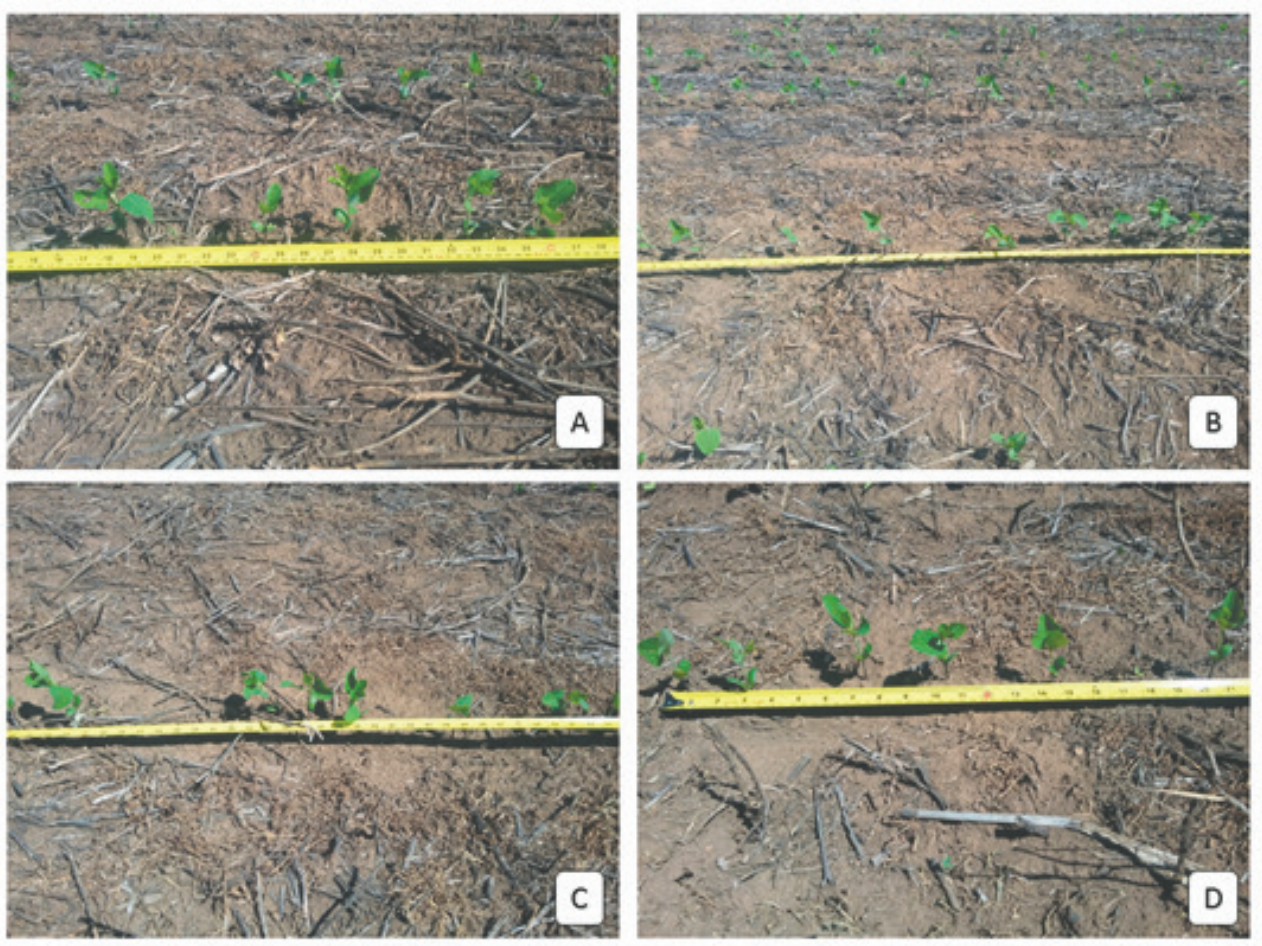

Figura 5. Distribuição das plantas em função da velocidade de semeadura, sendo $A=5,6 \mathrm{~km} \mathrm{~h}^{-1} ; B=7,0 \mathrm{~km}$ $\mathrm{h}^{-1} ; \mathrm{C}=8,6 \mathrm{~km} \mathrm{~h}^{-1}$ e D = 10,0 $\mathrm{km} \mathrm{h}^{-1}$ para a semeadora John Deere ${ }^{\circledR}$ modelo DB74. Baixa Grande do Ribeiro, PI, 2015.

menor entre uma célula e outra para depositar a semente, sendo assim, ele tem que girar mais rápido e acaba distribuindo irregularmente as sementes, principalmente ao comparar com semeadoras com discos com maior número de furos. Uma alternativa para este caso, seria a utilização de um disco com mais furos (108 furos), assim, há maior número de células, havendo giro mais lento do disco para deposição das sementes, reduzindo a interferência da velocidade de semeadura, que, ao utilizar discos com 36 furos, conforme aumenta-se a velocidade de semeadura, o disco pode girar muito rápido, prejudicando a qualidade de distribuição de sementes.

Para GARCIA (2015), as semeadoras devem desempenhar algumas funções básicas com eficiência, como abrir um sulco no solo, dosar a quantidade de sementes e posicioná-las no solo e cobrir o sulco, pressionando o solo ao redor das sementes, que repercuti em maior produtividade, assim como a velocidade de semeadura deve manter a qualidade da operação, independente da semeadora, ajustando-a. Vale a pena ressaltar, que mesmo em velocidade baixa, que aparentemente tem-se maior possibilidade de alcançar alta produtividade, também é imprescindível regulagem adequado do número de sementes a ser distribuído pelo sistema dosador de sementes.

Um outro ponto a ser destacado, é utilização de polímeros durante a semeadura. $\mathrm{O}$ uso destes produtos, facilita o deslocamento das sementes do interior da caixa até a deposição no solo, sendo polímero grafite mais conhecido e comumente utilizado na semeadura. Neste trabalho, as sementes de soja, não eram totalmente cobertas pelo grafite durante o tratamento de sementes (constatação de campo). O polímero foi adicionado dentro da caixa de sementes das semeadoras, no momento do abastecimento, como um complemento. A ausência de cobertura uniforme nas sementes com grafite, dificulta o movimento delas dentro da caixa, principalmente durante movimento do disco dentro da caixa de sementes, para coletar semente para cada célula (furo) durante o processo de distribuição. Sugere-se a adição de grafite seja homogeneizado 
A)

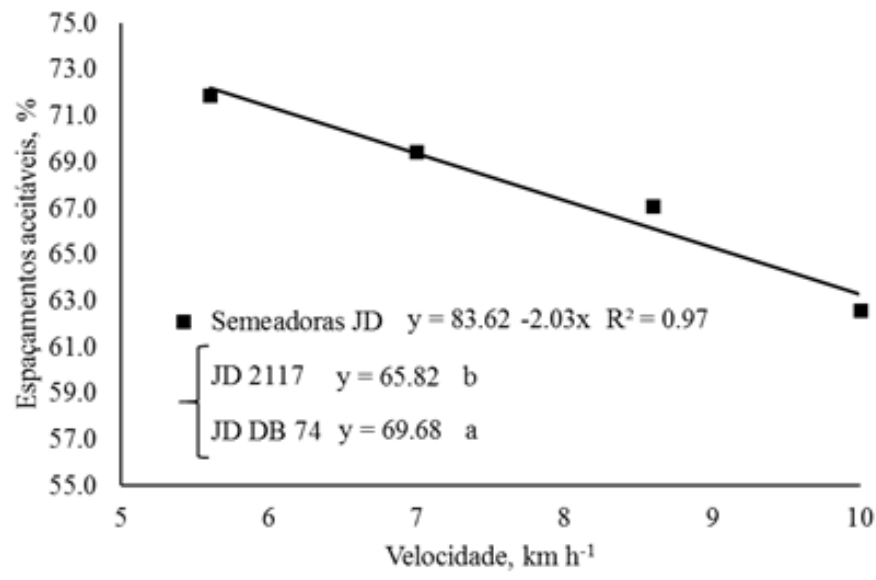

B)

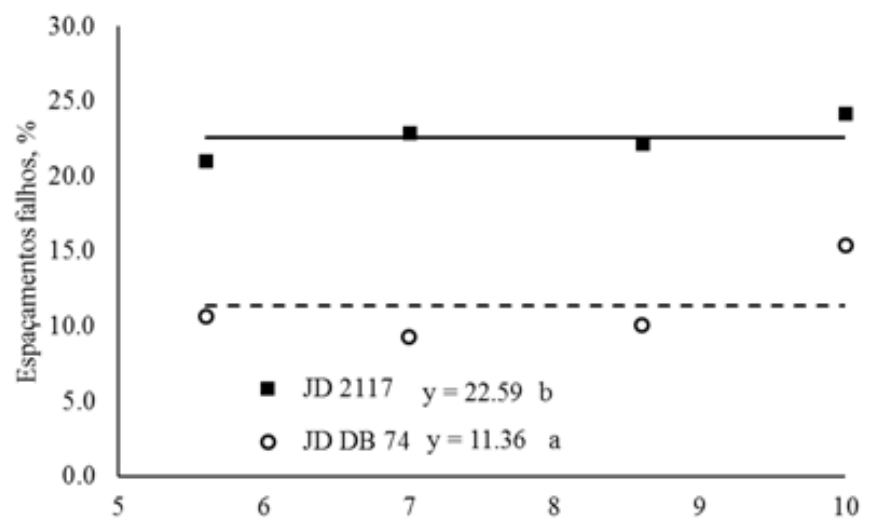

C)

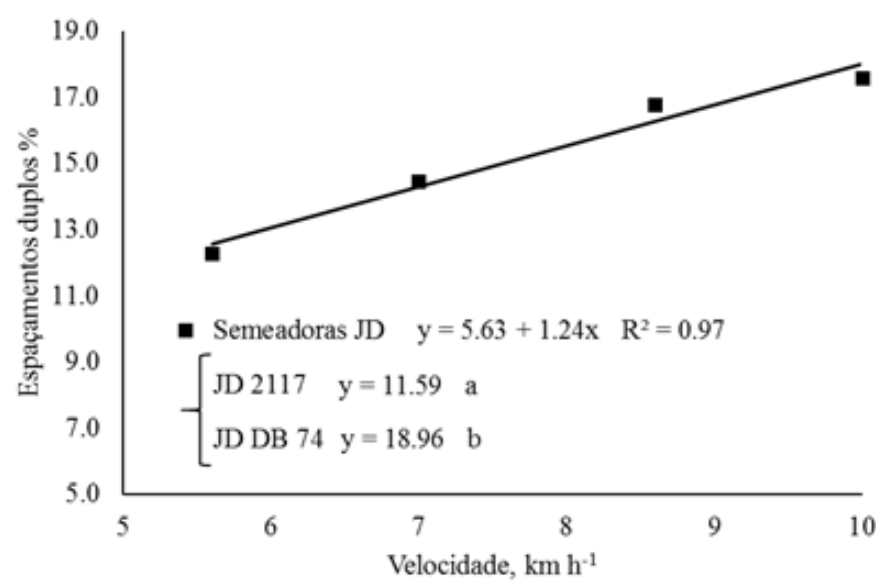

Figura 6. Espaçamentos aceitáveis (A), falhos (B) e duplos (C) em função da velocidade de semeadura para a

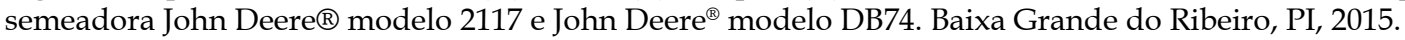

Applied Research \& Agrotechnology v9 n1 jan/apr. (2016)

Print-ISSN 1983-6325 (On line) e-ISSN 1984-7548 
nas sementes, podendo ser realizada no processo de tratamento de sementes, ou passando as sementes por novo processo para homogeneizar o grafite, assim como, possibilidade de desenvolvimento de sistema de distribuição de grafite na própria caixa de armazenagem de grãos.

\section{Conclusões}

Na semeadora John Deere ${ }^{\circledR}$ modelo 2117, com aumento da velocidade de semeadura de $5,6 \mathrm{~km}$ $\mathrm{h}^{-1}$ para $10,0 \mathrm{~km} \mathrm{~h}^{-1}$, o número de plantas por metro linear fica próximo ao estabelecido na regulagem da máquina. Já para a semeadora John Deere ${ }^{\circledR}$ modelo DB74, o valor de número de plantas fica abaixo do esperado, com média de 8,76 plantas $\mathrm{m}^{-1}$, (resultado de possível falha na regulagem/calibração da máquina antes de instalar o experimento).

Para ambas as semeadoras, a percentagem de espaçamentos aceitáveis diminui conforme se aumenta a velocidade de deslocamento, e os espaçamentos duplos aumentam com incremento na velocidade, consequentemente reduz a uniformidade de plantio.

\section{Referências}

BORTOLOTTO, T. C. Plantabilidade de milho na resteva de avezem cobertura e pastejado no sistema integração lavoura-pecuária, dessecados em diferentes épocas. Trabalho de conclusão de curso, Universidade Tecnológica Federal do Paraná, Pato Branco, PR, 2014. 46 f.

BRANQUINHO, K.B. Semeadura direta da soja (Glycine max L.) em função da velocidade de deslocamento e do tipo de manejo do milheto (Pennisetum glaucum (L) R. Brow). Dissertação (Mestrado em Ciência do Solo) - Faculdade de Ciências Agrárias e Veterinárias, Universidade Estadual Paulista, Jaboticabal, 2003. 62 f.

CASÃO JUNIOR, R.; ARAÚJO, A. G. de; RALISCH, R. Desempenho da semeadora-adubadora Magnum 2850 em plantio direto no basalto paranaense. Pesquisa Agropecuária Brasileira, Brasília, v.35, n.3, p.523-532, mar., 2000.

COPETTI, E. Máquinas e implementos - Problemas na semeadura: de quem é a culpa?. Portal dia de campo. Disponível em: <http://www.diadecampo.com.br/zpublisher/materias/Materia. asp?id=20644\&secao=M\%E1quinas\%20e\%20Implementos>. Acesso em: 10 jan. 2016.

COPETTI, E. Plantadoras: distribuição de sementes. Cultivar Máquinas, Pelotas, n.18, p.14-17, 2003.

CORTEZ, J. W.; FURLANI, C. E. A.; SILVA, R. P.; LOPES, A. Distribuição longitudinal de sementes de soja e características físicas do solo no plantio direto. Engenharia Agrícola, Jaboticabal, v.26, n.2, p.502-510, maio/ ago., 2006.

DEJNEKA, P. Brasil pode voltar a ser o maior exportador mundial de soja na safra 2015/2016. Globo Rural, 2015. Disponível em: <http://revistagloborural.globo.com/Colunas/direto-de-chicago/noticia/2015/05/ brasil-pode-voltar-ser-o-maior-exportador-mundial-de-soja-na-safra-20152016.html>. Acesso em: 14 ago. 2015.

FERREIRA, D. F. Sisvar: A computer statistical analysis system. Ciência e Agrotecnologia, v. 35, p. 1039-1042. 2011.

GARCIA, R. F. Semeadoras agrícolas. Universidade Estadual do Norte Fluminense Darcy Ribeiro, 200-. Disponível em: < http://garcia.xpg.uol.com.br/aula15_semeadoras.pdf>. Acesso em: 08 nov. 2015.

HEIFFIG, L. S.; CAMARA, G. M. S.; MARQUES, L. A.; PEDROSO, D. B.; PIEDADE, S. M. S. Fechamento e índice de área foliar da cultura da soja em diferentes arranjos espaciais. Bragantia, Campinas, v.65, n.2, p.285-295, 2006.

JASPER, R.; ASSUMPÇÃO, P.S. M.; ROCIL, J.; GARCIA, L. C. Velocidade de semeadura da soja. Engenharia Agrícola, Jaboticabal, v.31, n.1, p.102-110, jan./fev., 2011.

JOHN DEERE. Plantadeiras 2117. Disponível em: <https://www.deere.com.br/pt_BR/products/equipment/ planters/2100_series/2117/2117.page\#viewTabs>. Acesso em: 09 jan. 2016a.

Applied Research \& Agrotechnology $v 9$ n1 jan/apr. (2016)

Print-ISSN 1983-6325 (On line) e-ISSN 1984-7548 


\section{Desempenho da plantabilidade de... \\ Plantability performance of ... \\ p. $91-103$ \\ Rendimiento de sembradoras neumáticas en la...}

JOHN DEERE. Plantadeiras DB74. Disponível em: < https://www.deere.com.br/pt_BR/products/ equipment/planters/db_series/db_74/db_74.page>. Acesso em: 09 jan. 2016b.

KLEIN, V. A.; SIOTA, T. A.; ANESI, A. L.; BARBOSA, R. Efeito da velocidade na semeadura direta da soja. Engenharia Agrícola, Jaboticabal, v.22, n.1, p.75-82, 2002.

KOMATSU, R. A.; GUADAGNIN, D. D.; BORGO, M. A. Efeito do espaçamento de plantas sobre o comportamento de cultivares de soja de crescimento determinado. Campo Digit@1, v.5, n.1, p.50-55, Campo Mourão, dez., 2010.

KURACHI, S. A. H.; SILVEIRA, G. M.; COSTA, J. A. S.; BERNARDI, J. A.; SILVEIRA, G. M.; COELHO, J. L. D. Avaliação tecnológica de semeadoras e/ou adubadoras: tratamento de dados de ensaios e regularidade de distribuição longitudinal de sementes. Bragantia, Campinas, v.48, n.2, p.249-262, 1989.

LACERDA, M. Saiba como ajustar as máquinas para o plantio. Canal Rural, Sinop, 2015. Disponível em: < http:/ / www.projetosojabrasil.com.br/saiba-ajustar-maquinas-plantio/>. Acesso em: 17 dez. 2015.

MADALOZ, J. C. C. Qualidade de plantio na safrinha. Blog Agronegócio em Foco, 2014. Disponível em: < http:/ / www.pioneersementes.com.br/blog/12/qualidade-de-plantio-na-safrinha>. Acesso em: 26 jan. 2016.

MINUZZI, A.; RANGEL, M. A.; LUCCA e BRACCINI, A.; SCAPIM, C. A.; MORA, F.; ROBAINA, A. D. Rendimento, teores de óleo e proteínas de quatro cultivares de soja, produzidas em dois locais no Estado do Mato Grosso do Sul. Ciência e Agrotecnologia. Lavras, v. 33, n. 4, p. 1047-1054, 2009.

NUNES, J. L. da S. Características da soja (Glycine max). Agrolink. Disponível em: <http://www.agrolink. com.br/culturas/soja/caracteristicas.aspx>. Acesso em: 15 set. 2015.

PINTO, J. F. Falhas no estande de plantas. Cultivares. 2014. Disponível em: < http:/ /www.cultivares.com. br/noticias/index.php?c=4456>. Acesso em: 27 jan. 2015.

RAMBO, L.; COSTA, J. A.; PIRES, J. L. F.; PARCIANELLO, G.; FERREIRA, F. G. Rendimento de grãos da soja e seus componentes por estrato do dossel em função do arranjo de plantas e regime hídrico. Scientia Agraria, v.3, n.1-2, p.79-85, 2002.

SCHUCH, L. O. B.; PESKE, S. T. Falhas e duplos na produtividade. Revista SEED News, Pelotas, RS, n. 6, nov./dez. 2012

SILVA, J. G. da.; KLUTHCOUSKI, J.;STONE, L. F.; AIDAR, H.; OLIVEIRA, I. P. de; FERREIRA, E. Desempenho de semeadoras-adubadoras no estabelecimento da cultura do arroz de sequeiro. Pesquisa Agropecuária Brasileira, Brasília, v.33, n.1, p.63-70, 1998.

TOURINO, M. C. C.; REZENDE, P. M.; SALVADOR, N. Espaçamento, densidade e uniformidade de semeadura na produtividade e características agronômicas da soja. Pesquisa Agropecuária Brasileira, Brasília, v.37, n.8, p.1071-1077, 2002. 